\title{
Monitoring the Protective Effects of Minocycline Treatment with Radiolabeled Annexin V in an Experimental Model of Focal Cerebral Ischemia
}

\author{
Xian Nan Tang ${ }^{1,2}$, Qing Wang ${ }^{1}$, Maya A. Koike ${ }^{1}$, Danye Cheng ${ }^{3}$, Michael L. Goris ${ }^{3}$, Francis G. Blankenberg ${ }^{3}$, and \\ Midori A. Yenari ${ }^{1}$ \\ ${ }^{I}$ Department of Neurology, University of California, San Francisco, and San Francisco Veterans Affairs Medical Center, San Francisco, \\ California; ${ }^{2}$ Department of Anesthesia, Stanford University, Stanford, California; and ${ }^{3}$ Department of Radiology, Stanford University, \\ Stanford, California
}

\begin{abstract}
Minocycline is an antibiotic now recognized to have antiapoptotic and antiinflammatory properties. Because of these properties, minocycline may be of benefit in reducing neuronal apoptosis from ischemia and subsequent postischemic inflammation if administered soon after a stroke. We now explore the

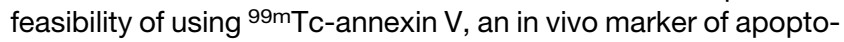
sis, with SPECT to monitor the antiapoptotic effects of minocycline therapy. Methods: CB6/F1 adult male mice underwent unilateral distal middle cerebral artery occlusion (dMCA) occlusion and were imaged and sacrificed at $1,3,7$, or $30 \mathrm{~d}$ after injury. Animals were given minocycline (or vehicle) $30 \mathrm{~min}$ and $12 \mathrm{~h}$ after dMCA occlusion and then given $22.5 \mathrm{mg} / \mathrm{kg}$ twice daily for up to $7 \mathrm{~d}$. Before imaging, behavioral tests were performed to evaluate the neurologic function. After imaging, brains were collected for histology and assessed for the degree of apoptosis and microglial activation. Results: ${ }^{99 m T c-A n n e x i n ~ V ~ u p t a k e ~ i n ~ i n j u r e d ~ h e m i-~}$ spheres was significantly decreased 2- to 3-fold by minocycline at all time points. Minocyline reduced infarct size as seen histologically and improved behavioral indices as late as $30 \mathrm{~d}$. Infarct volume as seen histologically correlated with radiolabeled annexin V uptake seen by SPECT. In situ fluorescent microscopy demonstrated that annexin $\mathrm{V}$ bound primarily to neurons at 1 and $3 \mathrm{~d}$, with a shift toward microglia by 7 and $30 \mathrm{~d}$. Conclusion: We found that minocycline significantly reduces neuronal apoptosis and infarct size and improves neurologic outcome in mice after acute focal cortical ischemia.
\end{abstract}

Key Words: apoptosis; neuroprotective agents; in vivo imaging; stroke

J Nucl Med 2007; 48:1822-1828

DOI: 10.2967/jnumed.107.041335

\section{A} postischemic cell death and postischemic inflammation

\footnotetext{
Received Feb. 28, 2007; revision accepted Jul. 30, 2007.

For correspondence or reprints contact: Midori A. Yenari, MD, Department of Neurology, University of California, San Francisco, Neurology (127), VA Medical Center, 4150 Clement St., San Francisco, CA 94121.

E-mail: yenari@alum.mit.edu

COPYRIGHT @ 2007 by the Society of Nuclear Medicine, Inc.
}

$(1,2)$. This observation has spawned the development of new specific antiapoptotic neuroprotective drugs (3). Minocycline is a member of the tetracycline family of antibiotics with recently recognized antiapoptotic and antiinflammatory properties. The antiapoptotic properties of minocycline appear to be due to its ability to inhibit caspase-3 (4), whereas its antiinflammatory effect appears to be due to a mechanism inhibiting p38 MAPK (MAPK is mitogen-activated protein kinase) activation in microglia (5). As such, minocycline has thus been shown to protect the brain against ischemic insults $(6,7)$ and improve functional impairment $(8)$. Apoptosis can be imaged indirectly with radiolabeled annexin $\mathrm{V}$ in animal models and humans using SPECT. Annexin V is a human protein that has a high affinity for the membrane anionic phospholipid phosphatidylserine (PS), which is selectively exposed after activation of caspase-3 (9-11). In the current study, we apply annexin V SPECT to monitor the treatment response to minocycline treatment of mice subjected to an acute unilateral distal middle cerebral arterial (dMCA) ischemic injury.

\section{MATERIALS AND METHODS}

\section{Murine Model of Experimental Stroke}

CB6/F1 male mice (Jackson Laboratories), 25-30 g, were housed and treated in a humane manner in strict accordance with institutional guidelines. Ninety-nine mice were used for this study. Two mice were used as sham controls for the behavior assays, and their brains were collected to use as negative controls for the histology/ immunostains. Forty-four mice were scanned using SPECT and were harvested at various times for histology and other assays. Fiftyone mice were used for the behavior studies, and brains were harvested at various times for histology and terminal deoxynucleotidyl transferase-mediated dUTP nick-end labeling (TUNEL) stains (detailed numbers by time point are broken down in the individual figures). Mice were anesthetized with 5\% isofluorane delivered into an anesthesia induction chamber with oxygen and air supplied at a ratio of $0.2 \mathrm{~L} / \mathrm{min}$ oxygen: $0.8 \mathrm{~L} / \mathrm{min}$ air. Once surgical planes of anesthesia were attained (assessed by absence of hind leg withdrawal to pinch), isoflurane was decreased to $2 \%-2.5 \%$ throughout the remainder of the surgery. The dMCA was occluded as previously 
described by Zhao et al. (12) with some modifications. Briefly, a cervical midline incision was made to expose both common carotid arteries (CCAs). The animal was then placed on its right side and a $1-\mathrm{cm}$ vertical skin incision was made in the midpoint between the left orbit and the external auditory canal. The temporalis muscle was bisected and a 1-mm burr hole was made at the junction of the zygomatic arch and the squamous bone, and the dMCA was exposed at the rhinal fissure. The dMCA superior to the rhinal fissure was then occluded by a bipolar electric coagulator. The animal was then placed in the supine position, and both CCAs were temporarily occluded with aneurysm clips for $45 \mathrm{~min}$. Clips were then removed and wounds were closed and animals were then allowed to recover. Mice received $45 \mathrm{mg} / \mathrm{kg}$ minocycline $\mathrm{HCl}$ (Sigma), dissolved in $0.01 \mathrm{M}$ phosphate-buffered saline (PBS), intraperitoneally $30 \mathrm{~min}$ and $12 \mathrm{~h}$ after MCA occlusion and from then on received $22.5 \mathrm{mg} / \mathrm{kg}$ twice a day for up to $7 \mathrm{~d}$; controls received PBS as vehicle.

Animals also underwent small-animal SPECT at 1, 3, 7, or $30 \mathrm{~d}$ after ischemic injury. After imaging, animals were sacrificed with an overdose of isoflurane. Immediately after sacrifice, brains were carefully removed for histology and other immunohistochemical assays.

\section{Behavior Studies}

All sensorimotor functional assessments were performed by investigators who were unaware of treatment groups.

Corner Test. The corner test was performed using the methodology as developed by $\mathrm{Li}$ et al. (13). Briefly, 2 sheets of cardboard (each $20 \times 30 \times 1 \mathrm{~cm}$ ) were placed in the home cage of the animal and positioned to create a $30^{\circ}$ corner with a $0.5-$ to $1-\mathrm{cm}$ gap to permit light to shine through. The animal was placed between the boards and encouraged to enter the corner. Once the animal reached the corner, the vibrissae were stimulated bilaterally by the cardboard sheets, causing the animal to rear forward and upward, and finally to turn around and face the open end of the boards. Each animal was serially tested 20 times and the number of turns toward the ipsilateral ischemic hemisphere (left) were counted.

Ladder Test. Another measure of sensorimotor function used in this study was the ladder test (14) with minor modifications. A ladder composed of 40 rungs with a $1-\mathrm{mm}$ diameter and $2-\mathrm{cm}$ intervals was constructed. The ladder was placed between 2 transparent acrylic walls spaced $4 \mathrm{~cm}$ apart, so that once the mouse was placed on the ladder, it could only move straight ahead. The ladder was placed at a $45^{\circ}$ slope and the animal was encouraged to move forward and upward. Each weight-bearing step was recorded by a video camera placed underneath the ladder. The number of forelimb faults associated with each-weight bearing were then reviewed and tabulated.

\section{Infarct Volume Assessment}

After mice were euthanized and perfused, brains were removed and sunk in $20 \%$ sucrose at $4^{\circ} \mathrm{C}$ for $24-48 \mathrm{~h}$. Cryosections $(25-\mu \mathrm{m}$ thick) were prepared from brains of animals that survived 1 and $3 \mathrm{~d}$ and stained with cresyl violet. Infarct volume was determined using previously published methods (15). Brains of animals that survived 7 and $30 \mathrm{~d}$ were stained with hematoxylin and eosin, as cresyl violet does not reliably delineate regions of infarction by $7 \mathrm{~d}$.

\section{Histochemistry}

Brain sections were fixed with $75 \%$ acetone/25\% ethanol for 15 min and then blocked in 5\% normal goat serum, $5 \%$ normal horse serum, and $1 \%$ bovine serum albumin in PBS. Sections were reacted with primary antibodies conjugated to a fluorescent probe overnight at $4{ }^{\circ} \mathrm{C}$ in a foil-wrapped box. Neurons were detected by mouse antineuronal nuclei (NeuN) conjugated to Alexa Fluor 488 (1:100, MAB377X, mouse monoclonal; Chemicon); astrocytes were detected by antiglial fibrillary acidic protein (GFAP) conjugated to Alexa Fluor 488 (1:200, A-21294, mouse monoclonal; Invitrogen); microglia were detected by fluorescein isothiocyanate (FITC)-conjugated isolectin B4 from Bandeiraea simplicifolia (IB4, $20 \mu \mathrm{g} / \mathrm{mL}$, L2895; Sigma) or tomato lectin conjugated to FITC (lectin, $20 \mu \mathrm{g} / \mathrm{mL}$, L0401; Sigma). After washing, sections were incubated in annexin $\mathrm{V}$ conjugated to $\mathrm{Cy} 3.18$ from human placenta (1:100 diluted in a solution of $100 \mathrm{mM} \mathrm{N}$-(2-hydroxyethyl)piperazine- $N^{\prime}$-(2-ethanesulfonic acid) [HEPES]/NaOH, pH 7.5, $1.4 \mathrm{M} \mathrm{NaCl}$, and $25 \mathrm{mM} \mathrm{CaCl}_{2}, \mathrm{~A} 4963$; Sigma). To delineated areas of annexin $\mathrm{V}$ binding, FITC-labeled annexin $\mathrm{V}$ was applied directly to brain sections (1:100 dilution containing 100 $\mathrm{mM}$ HEPES/NaOH, pH 7.5, $1.4 \mathrm{M} \mathrm{NaCl}$, and $25 \mathrm{mM} \mathrm{CaCl}_{2}$, A9210; Sigma) or injected into animals $1 \mathrm{~h}$ before sacrifice (100 $\mu \mathrm{g} / \mathrm{kg}$ protein per animal, intraperitoneally). Brain sections were mounted with VectaShield Mounting Medium with 4,6-diamino-2phenylindole (DAPI) (H-1200) and visualized under a fluorescent microscope (Axiovert 40 CFL; Carl Zeiss).

To identify microglia and other cells of monocyte lineage, adjacent brain sections were stained with horseradish peroxidaseconjugated IB4 (20 $\mu \mathrm{g} / \mathrm{mL}$; Sigma) using a previously published protocol (16).

\section{TUNEL Staining}

TUNEL staining was performed with the ApopTag peroxidase in situ apoptosis detection kit (S7100; Chemicon) according to kit instructions. Cryosections were fixed in $1 \%$ paraformaldehyde and then treated with precooled ethanol/acetic acid, 2:1, for $5 \mathrm{~min}$ at $-20^{\circ} \mathrm{C}$ and then incubated in $3 \%$ hydrogen peroxide followed by incubation at $37^{\circ} \mathrm{C}$ in terminal deoxynucleotidyl transferase enzyme for $1 \mathrm{~h}$. Sections were reacted with antidigoxigenin peroxidase conjugate for $30 \mathrm{~min}$ at room temperature and developed in peroxidase substrate. Sections were counterstained with methyl green.

\section{Cell Counting}

The number of IB4-positive cells within 6 high-power fields $(\times 400)$ of the periinfarct area was counted as described previously (16). Typically, microglia form a distinct dense band surrounding the ischemic lesion, permitting some consistency in defining the periinfarct region from animal to animal. For TUNEL-stained sections, all TUNEL-positive cells as well as TUNEL-positive cells with morphologic criteria consistent with apoptosis (17) were counted within the same periinfarct regions as the IB4 counts. The number of positive cells in 6 consecutive fields around the striatum and cortex at $\times 400$ magnification was counted. Each section was counted 3 times and averaged. Three sections were analyzed in each group of mice. All counts were performed by an experienced observer who was unaware of the treatment groups.

\section{Preparation of Radiolabeled Annexin V}

NAS 2020 kits were generously supplied by Theseus Imaging Corp. The 2-vial kit includes a vial of $0.5 \mathrm{~mL}(0.25 \mathrm{mg})$ of frozen liquid hydrazinonicotinamide-recombinant human (HYNIC-rh)annexin V conjugate solution (vial 1) and a vial of lyophilized stannous tricine containing approximately $20 \mathrm{mg}$ tricine and 500$650 \mu \mathrm{g}$ stannous chloride (vial 2). Radiolabeling was conducted at room temperature. ${ }^{99 \mathrm{~m}} \mathrm{Tc}-$ Pertechnetate $(1,110-1,850 \mathrm{MBq}$ 
[30-50 mCi]; 0.4-0.6 mL) was added to the HYNIC-rh-annexin V conjugate (vial 1). The lyophilized stannous tricine (vial 2) was reconstituted with $3 \mathrm{~mL}$ of sterile saline. Then, an aliquot of 0.3 $\mathrm{mL}$ of stannous tricine solution was added to the HYNIC-rhannexin $\mathrm{V}$ vial. The vial was mixed gently, allowed to incubate at room temperature, diluted by the addition of $2 \mathrm{~mL}$ sodium chloride for injection, and tested for quality by visual inspection, $\mathrm{pH}$, and radiochemical purity testing with instant thin-layer chromatography (ITLC) silica gel and acid citrate/dextrose (ACD) solution and $\mathrm{pH}$ strips necessary for the quality control of the product. Radiochemical purity of the drug product was verified to be $>90 \%$ as determined by ITLC (ACD).

\section{Small-Animal SPECT}

Before imaging, animals were sedated for imaging with $0.1 \mathrm{~mL}$ of a cocktail of ketamine $(24 \mathrm{mg} / \mathrm{mL}) / x y l a z i n e ~(3 \mathrm{mg} / \mathrm{mL})$ in PBS injected intraperitoneally. Images were obtained using the LumaGEM small-animal SPECT system (Gamma Medica Instruments). This system is equipped with a single-head detector with a maximal $13 \times 13 \mathrm{~cm}$ field as well as a maximal resolution of $0.4 \mathrm{~mm}$ with a $1-\mathrm{mm}$ pinhole collimator. SPECT images were recorded into a $64 \times 64$ imaging matrix for the projection data (and $64^{3}$ for the ordered-subsets expectation maximization reconstructed data), $3^{\circ}$ per step, $30 \mathrm{~s}$ per step for a $360^{\circ}$ rotation with a radius of rotation of $2.0 \mathrm{~cm}$. Animals were administered $185-370 \mathrm{MBq}(5-10 \mathrm{mCi})$ of ${ }^{99 \mathrm{~m}} \mathrm{Tc}-\mathrm{HYNIC}$-annexin $\mathrm{V}(20-50 \mu \mathrm{g} / \mathrm{kg}$ of protein) $1 \mathrm{~h}$ before imaging by penile vein injection. Pinhole data reconstruction was performed using the software and methods described previously (11). To define the activity distribution in the brain in our SPECT data, we have developed tools for the analysis of 3-dimensional images consisting of parametric 3-dimensional regions of interest (ROIs), interactively placed and sized. Typical regions used were spheric regions with shells that were spheric or ellipsoid.

Two ROIs were drawn within the cerebral hemispheres of each animal: one that circumscribed the ischemic lesion of the left cerebral cortex and the other placed within the contralateral hemisphere used as background activity (BKG) for subsequent calculations. The total number of counts, adjusted for volume, was summed between the 34th and 68th percentiles determined from the histograms of both the lesion and BKG ROIs. The total number of counts per voxel for each lesion was then normalized by dividing by the number of counts per voxel of the respective BKG ROI. This ratio was then multiplied by the fractional lesion volume (relative to the total volume of the cerebral hemispheres) to obtain the total normalized lesion activity for each SPECT examination.

\section{Statistical Analysis}

All statistical analyses were performed using Sigma Stat 2.03 (Systat Software, Inc.). Quantitative data are presented as mean \pm SE. Two-group comparisons were performed by a 2-tailed Student $t$ test. Multiple-group comparisons were performed using 1-way ANOVA followed by the Tukey HSD (honestly significant difference) post hoc test. $\chi^{2}$ or nonparametric tests were used for noncontinuous data. $P<0.05$ was considered statistically significant.

\section{RESULTS}

\section{Minocycline Reduces Infarct Volume}

In the control groups, the infarct volume, as seen histologically, increased from 1 to $7 \mathrm{~d}$ after the experimental stroke but, by $30 \mathrm{~d}$, the infarct volume decreased to that seen in the 1-d group. Infarct sizes in the 7-d group were larger infarcts than the 1-, 3-, and 30-d groups (Fig. 1C). Minocycline reduced infarct volume at all time points compared with vehicle-treated controls (Figs. 1A and 1C).

\section{Minocycline Improves Sensorimotor Function}

Treatment with minocycline significantly improved sensorimotor function as measured by the corner and ladder tests. For the corner test, minocycline-treated animals showed less frequent turning to the lesion side than the control animals at 3, 7, and $30 \mathrm{~d}$ after ischemia. Shamoperated animals showed no difference in turning between sides (Fig. 2A). For the ladder test, minocycline-treated animals showed fewer forelimb faults at 3, 7, and $30 \mathrm{~d}$ after
FIGURE 1. Minocycline treatment reduces infarct volume. (A) Representative cresyl violet-stained brain sections of mice subjected to ischemia show a smaller infarct in minocycline-treated mouse (b) compared with vehicle-treated mouse (a). (B) Representative mouse brain SPECT images at 1, 3, 7, and $30 \mathrm{~d}$ after stroke show less annexin $\mathrm{V}$ uptake (right side of image) after minocycline treatment compared with vehicle-treated controls. (C) Infarct sizes increased with a peak at $7 \mathrm{~d}$ ( $P<0.05$ vs. other time points). Infarct volume was reduced by minocycline treatment (black bars) compared with vehicletreated controls (white bars) on 1, 3, 7, and $30 \mathrm{~d}$ after stroke ( ${ }^{\star \star} P<0.01, n=5 /$ group). (D) Annexin $V$ binding was increased after ischemia with peaks at 1 and $7 \mathrm{~d}$. Minocycline treatment (black bars) reduced binding at all time points compared with

vehicle-treated controls (white bars). Data for each hemisphere at each time point are graphed as average of maximal lesion uptake (ROI normalized to background).

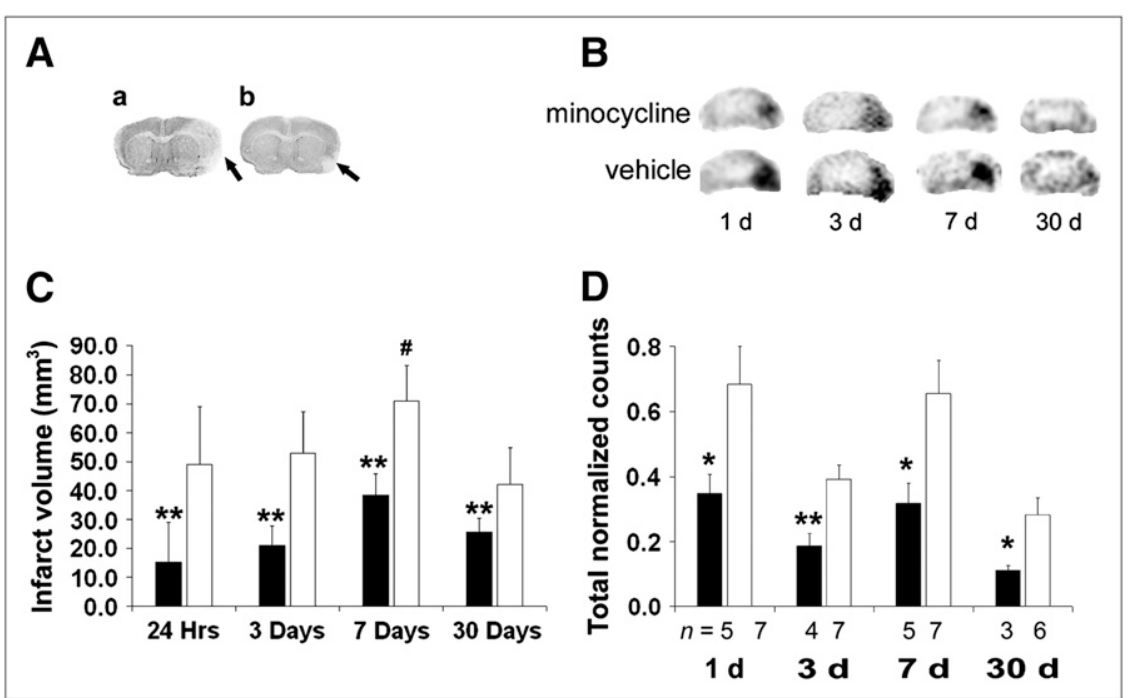



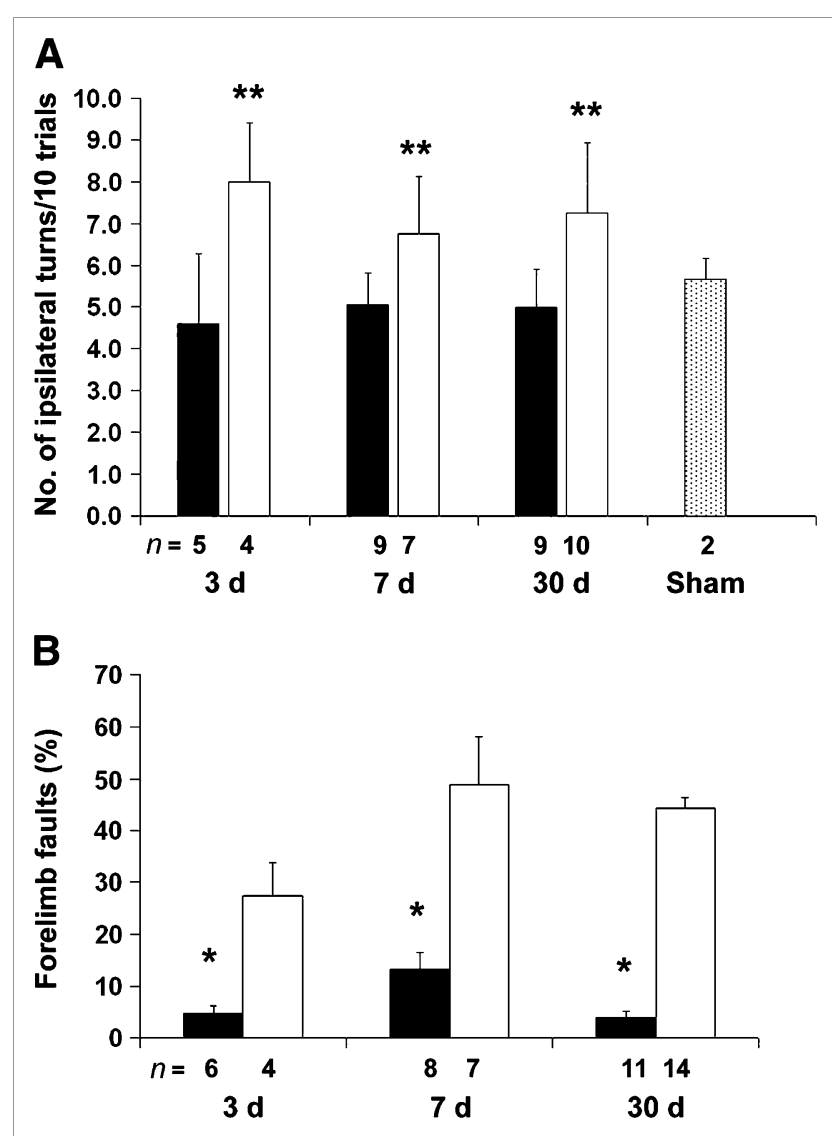

FIGURE 2. Minocycline treatment improves neurologic function. (A) Corner test: Each mouse was tested 20 times, and data were converted to the number of turns toward the ipsilateral ischemic hemisphere for 10 trials. Minocycline-treated animals (black bars) showed less turning to lesion side than vehicletreated animals (white bars) $\left({ }^{\star \star} P<0.01\right)$. Compared with shamoperated animals (gray bar), minocycline-treated animals performed no differently on the corner test. (B) Ladder test: Each mouse was tested 3 times and counts were averaged. Minocycline-treated animals (black bars) showed fewer forelimb faults per 100 steps than vehicle-treated mice (white bars) $\left({ }^{\star} P<0.05\right)$.

the stroke than the control mice (Fig. 2B). Sham-operated animals had few, if any, foot faults (data not shown).

\section{Annexin V SPECT Uptake}

Minocycline reduced annexin V uptake by 2- to 3-fold at each time point. Annexin V uptake was maximal on days 1 and 7, with a relative trough on day 3 in both control and minocycline-treated groups. This was followed by a decline at $30 \mathrm{~d}$ below day 3 values in both groups. (Figs. 1B and 1D)

\section{Localization of Annexin V Binding}

Because annexin V could bind internal PS residues exposed by cryosectioning if applied directly to brain sections, we compared the direct application of labeled annexin to tissue sections versus injecting animals with annexin before euthanasia. In brains of uninjured mice, FITC-labeled annexin $\mathrm{V}$, when applied directly to brain sections or when injected into animals $1 \mathrm{~h}$ before sacrifice $(100 \mu \mathrm{g} / \mathrm{kg}$ protein per animal, intraperitoneally), showed similar staining patterns. As shown in Figures 3A and 3B, the binding pattern is similar with both methods. Some background staining is present with occasional punctuate binding to intracellular structures in both cases. In contrast, annexin $\mathrm{V}$ applied directly to brain sections in mice subjected to stroke revealed positive cells with delineation of the entire cell (Fig. 3B). Therefore, for double-labeling studies, we chose to apply labeled annexin $\mathrm{V}$ directly to tissue sections.

Ischemic brain sections were costained with Alexa Fluor 488-conjugated Neun, GFAP, or FITC-labeled tomato lectin (which tends to identify all cells of monocyte lineage compared with IB4, which tends to stain activated cells more robustly), plus Cy3.18-conjugated annexin V. Doublelabeled cells in 6 consecutive fields within the periinfarct area were counted at $\times 400$. One and $3 \mathrm{~d}$ after the stroke, annexin $\mathrm{V}$ colocalized primarily to Neun-positive cells $(43 \% \pm 13.4 \%$ and $59 \% \pm 12.5 \%$, respectively). At later time points (i.e., 7 and $30 \mathrm{~d}$ after stroke), fewer neurons bound annexin V. On 7 and $30 \mathrm{~d}$ after the stroke, annexin $\mathrm{V}$ colocalized primarily to lectin-positive cells $(55 \% \pm 5 \%$ and $49 \% \pm 11 \%$, respectively). Astrocytes, on the other hand, rarely bound annexin $\mathrm{V}$ at any time point (Figs. 3C and 3D).

\section{Minocycline Treatment Reduces Apoptosis and Inflammation}

Minocycline treatment significantly reduced the number of TUNEL-positive cells as well as TUNEL-positive cells displaying characteristic nuclear morphology of apoptosis (Figs. 4A and B). IB4 staining showed that microglia/ monocytes/macrophages increased in number, reaching a peak $7 \mathrm{~d}$ after a stroke. This was also significantly reduced by treatment with minocycline (Fig. 5).

\section{DISCUSSION}

Minocycline, a member of the tetracycline family of antibiotics, has been shown to reduce injury due to cerebral ischemia via several antiinflammatory and antiapoptotic actions $(6,7,18,19)$. These include the inhibition or reduction of the metalloproteinase MMP-9 (6), caspase-3, oxidative stress (20), cytochrome $c$ translocation (21), and p38 MAPK activity $(5,22)$. In a previous study we have also shown that minocycline can prevent microglial activation and not only reduce infarct size after an experimental stroke but also limit BBB disruption and hemorrhage (18).

In the current study animals treated with minocycline for $1 \mathrm{wk}$ showed significant improvement of neurologic function that persisted as far out as $30 \mathrm{~d}$. Infarct volume was also reduced up to $30 \mathrm{~d}$. These observations are in line with those by Liu et al. (8), who found improvement in functional deficits when minocycline treatment was delayed $4 \mathrm{~d}$ after stroke onset, and animals survived $6 \mathrm{wk}$. These results are different from those of a study of neonatal stroke in which only a temporary protection by minocycline was 


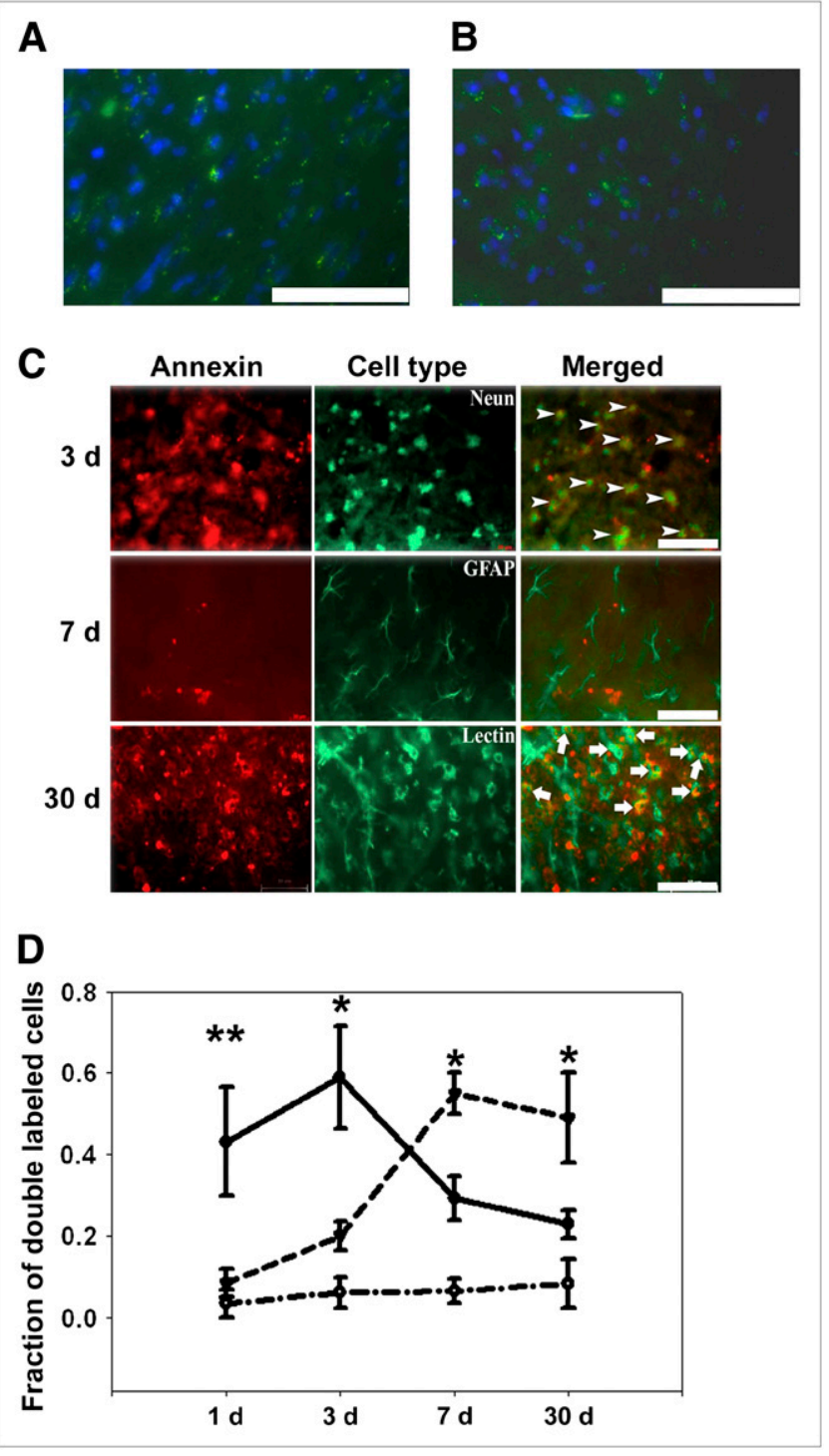

FIGURE 3. Annexin $\mathrm{V}$ binds to different cell types over time. Comparison of annexin $V$ staining when substrate was applied directly to tissue sections $(A)$ or injected into animals $1 \mathrm{~h}$ before sacrifice (B) $(100 \mu \mathrm{g} / \mathrm{kg}$ protein per animal, intraperitoneally). The annexin $\mathrm{V}$ binding pattern (green) for both methods is similar, with some background staining and staining of some intracellular organelles seen in both. Clearly, the staining pattern in both methods is distinct from that seen after ischemia (C) (DAPI, blue). (C) Representative images of annexin $\mathrm{V}$ binding to different types of cells after ischemia. Brain sections were stained with Alexa Fluor 488-conjugated Neun, GFAP, or FITClabeled tomato lectin ( $n=5 /$ group) and then colabeled with annexin $\mathrm{V}$ conjugated to Cy3.18. Three days after stroke, annexin $\mathrm{V}$ bound primarily neurons (Neun, arrowheads), whereas $30 \mathrm{~d}$ after stroke, annexin $\mathrm{V}$ bound microglia (Lectin, arrows). Rare astrocytes (GFAP) bound annexin $\mathrm{V}$ (representative image shown here $7 \mathrm{~d}$ after stroke). (D) Annexin $\mathrm{V}$ binds neurons acutely and microglia subacutely after experimental stroke. Double-labeled cells in 6 consecutive nonoverlapping $\times 400$ fields within periinfarct zone were counted and expressed as fraction of all cells labeled for the respective cell-type marker. One and $3 \mathrm{~d}$ after stroke, annexin $\mathrm{V}$ bound primarily neurons (solid line) but, at later time points (7 and $30 \mathrm{~d}$ ), annexin $\mathrm{V}$ bound primarily microglia/monocytes (dashed line). There

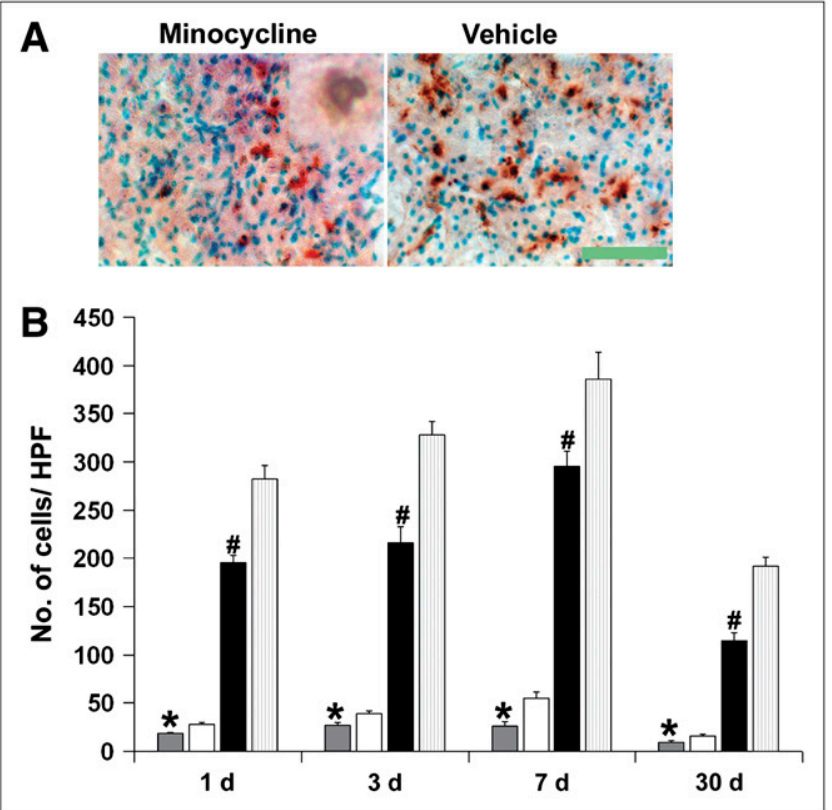

FIGURE 4. Minocycline reduces numbers of TUNEL-positive cells. (A) Representative TUNEL-stained images taken from periinfarct regions of ipsilateral ischemic cortex of minocyclinetreated and vehicle-treated animals $3 \mathrm{~d}$ after stroke (inset shows representative cell with apoptotic nuclear morphology; $\times 1,000$ magnification), scale bar $=100 \mu \mathrm{m}$. (B) Minocycline treatment significantly reduces all TUNEL-positive cells per microscopic field (black bars $=$ minocycline, light gray bars $=$ vehicle; ${ }^{\#} P<0.01$ ) as well as numbers of TUNEL-positive cells displaying characteristic apoptotic nuclear morphology (dark gray bars $=$ minocycline, white bars $=$ vehicle, $\left.{ }^{\star} P<0.01\right)$ in ischemic hemisphere $1,3,7$, and $30 \mathrm{~d}$ after stroke $(n=3$ per group). HPF $=$ high-power field.

observed (22). The transient benefits of minocycline in the neonatal rodent model may be related to the short period of minocycline treatment used in the study or inherent differences in the immature brain compared with the adult brain.

We previously showed that ${ }^{99 \mathrm{~m}} \mathrm{Tc}-$ labeled annexin $\mathrm{V}$ uptake correlated with neuronal apoptosis after a stroke $(9,10)$. In this study we have extended our period of observation to $30 \mathrm{~d}$ after a stroke and have further defined the cell types that bind annexin V. Our data have shown that there is a shift in the proportion of annexin $\mathrm{V}$-binding cells from predominately neurons at $24 \mathrm{~h}$ to microglial cells $7 \mathrm{~d}$ after a stroke. The peak annexin $\mathrm{V}$ uptakes seen on day 1 and day 7 correlate with the peak number of doubly stained neurons and microglial cells, respectively. The trough on day 3 appears to represent an intermediate time point in which apoptotic neurons disappear and microglial cells begin to infiltrate and proliferate in the penumbra of

were few annexin $\mathrm{V}$-positive astrocytes, and this pattern did not change over time (dashed-dotted line). ${ }^{\star} P<0.05,{ }^{\star \star} P<$ $0.01 \mathrm{vs}$. other cell types at a given time point. $(A-C$, scale bar $=$ $75 \mu \mathrm{m})$. 


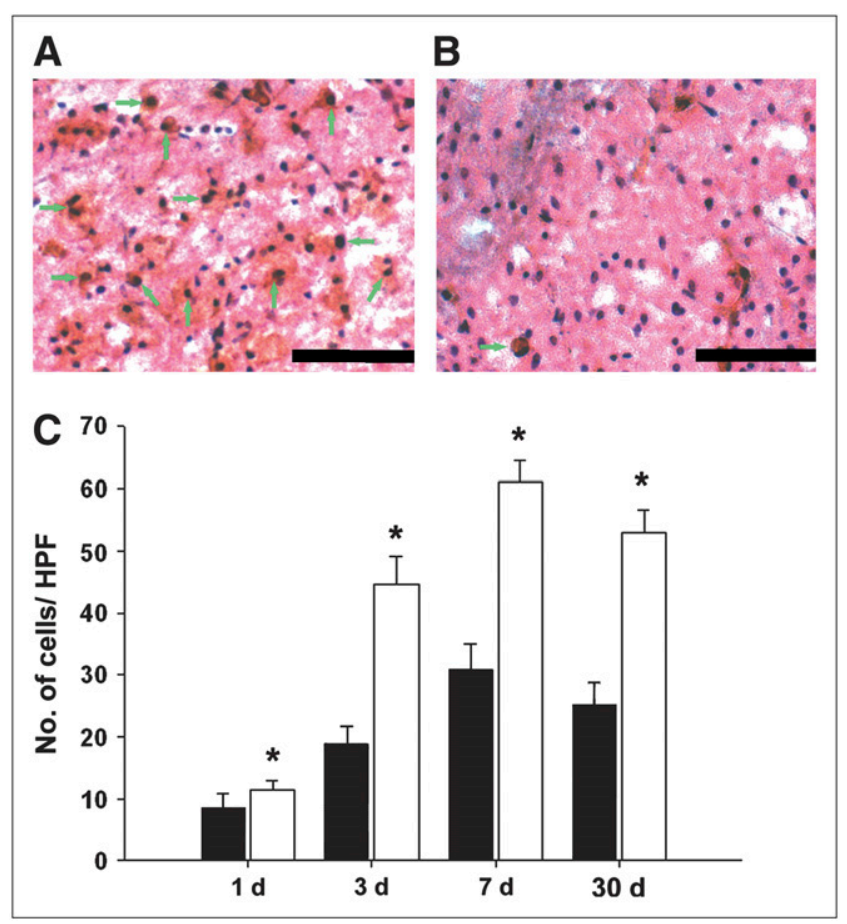

FIGURE 5. Minocycline treatment reduces monocyte/microglial activation and infiltration. Representative images $7 \mathrm{~d}$ after stroke show abundant activated microglia/monocytes within periinfarct area of vehicle-treated mouse (A) compared with few positive cells in minocycline-treated mouse (B) (arrows; IB4 stain). Scale bar $=215 \mu \mathrm{m}$. (C) Compared with vehicle (white bars), minocycline treatment (black bars) significantly reduced monocyte/microglial activation and infiltration into brain parenchyma around infarct area ( ${ }^{*} P<0.001, n=3$ /group). HPF $=$ high-power field.

an infarct. The high annexin uptake seen on day 7 is most likely due to microglial apoptosis that is part of the normal regulation of the immune system. Astrocytes did not display a significant degree of annexin $\mathrm{V}$ binding in our stroke model.

Annexin V imaging, though not specific to cell type, was able to assess the temporal changes in overall apoptosis after ischemic injury. These data suggest that ${ }^{99 \mathrm{~m}} \mathrm{Tc}$-labeled annexin V SPECT detects primarily neuronal cell death up to $3 \mathrm{~d}$ after a stroke, after which annexin $\mathrm{V}$ binds primarily inflammatory cells. Several methods have been used to detect ischemia at the clinical level, and recent work in the area of stroke research has focused on apoptosis and inflammation as being critical events ultimately leading to brain cell death. Although these processes can be detected routinely in the laboratory, this is not always possible using available imaging methodologies. ${ }^{99 \mathrm{~m}} \mathrm{Tc}-$ Labeled annexin V SPECT has already been studied to monitor apoptosis in oncotherapy $(23,24)$ and transplantation $(25)$. In our previous work, we showed that treatment with an antiapoptotic therapy (antibody against Fas ligand) reduced injury in a rodent stroke model, and this was correlated with decreased annexin uptake using SPECT. We also used this technique to detect apoptosis in stroke patients to show that in patients imaged within $8 \mathrm{~h}$ of symptom onset, SPECT of radiolabeled annexin $\mathrm{V}$ showed binding within regions of ischemia detected by diffusion-weighted MRI (11).

\section{CONCLUSION}

We show that minocycline, an antibiotic with antiapoptotic and antiinflammatory properties, improves long-term outcome after an experimental stroke. Furthermore, we show that ${ }^{99 \mathrm{~m}} \mathrm{Tc}$-labeled annexin V SPECT can be used as a noninvasive tool to monitor apoptosis in the acute and subacute stages of stroke and the brain's response to potential therapy.

\section{ACKNOWLEDGMENTS}

This work was supported by National Institutes of Health grants NIBIB R01 EB000898, NINDS R01 NS40516, P50 NS014543, and P01 NS37520, an American Heart Association Established Investigator Award, and Stanford University Dean's Postdoctoral Fellowship.

\section{REFERENCES}

1. Du C, Hu R, Csernansky CA, Hsu CY, Choi DW. Very delayed infarction after mild focal cerebral ischemia: a role for apoptosis? J Cereb Blood Flow Metab. 1996;16:195-201.

2. Chan PH. Mitochondria and neuronal death/survival signaling pathways in cerebral ischemia. Neurochem Res. 2004;29:1943-1949.

3. Chan PH. Future targets and cascades for neuroprotective strategies. Stroke. 2004;35(11 suppl 1):2748-2750.

4. Wang X, Zhu S, Drozda M, et al. Minocycline inhibits caspase-independent and -dependent mitochondrial cell death pathways in models of Huntington's disease. Proc Natl Acad Sci USA. 2003;100:10483-10487.

5. Tikka T, Fiebich BL, Goldsteins G, Keinanen R, Koistinaho J. Minocycline, a tetracycline derivative, is neuroprotective against excitotoxicity by inhibiting activation and proliferation of microglia. J Neurosci. 2001;21:2580-2588.

6. Koistinaho M, Malm TM, Kettunen MI, et al. Minocycline protects against permanent cerebral ischemia in wild type but not in matrix metalloprotease-9deficient mice. J Cereb Blood Flow Metab. 2005;25:460-467.

7. Yrjanheikki J, Tikka T, Keinanen R, Goldsteins G, Chan PH, Koistinaho J. A tetracycline derivative, minocycline, reduces inflammation and protects against focal cerebral ischemia with a wide therapeutic window. Proc Natl Acad Sci USA. 1999;96:13496-13500.

8. Liu Z, Fan Y, Won SJ, et al. Chronic treatment with minocycline preserves adult new neurons and reduces functional impairment after focal cerebral ischemia. Stroke. 2007;38:146-152.

9. D'Arceuil H, Rhine W, de Crespigny A, et al. ${ }^{99 \mathrm{~m}} \mathrm{Tc}$ annexin V imaging of neonatal hypoxic brain injury. Stroke. 2000;31:2692-2700.

10. Mari C, Karabiyikoglu M, Goris ML, Tait JF, Yenari MA, Blankenberg FG. Detection of focal hypoxic-ischemic injury and neuronal stress in a rodent model of unilateral MCA occlusion/reperfusion using radiolabeled annexin V. Eur J Nucl Med Mol Imaging. 2004;31:733-739.

11. Blankenberg FG, Kalinyak J, Liu L, et al. ${ }^{99 \mathrm{~m}} \mathrm{Tc}-\mathrm{HYNIC}$-annexin V SPECT imaging of acute stroke and its response to neuroprotective therapy with anti-Fas ligand antibody. Eur J Nucl Med Mol Imaging. 2006;33:566-574.

12. Zhao H, Yenari MA, Cheng D, Sapolsky RM, Steinberg GK. Bcl-2 overexpression protects against neuron loss within the ischemic margin following experimental stroke and inhibits cytochrome c translocation and caspase-3 activity. J Neurochem. 2003;85:1026-1036.

13. Li X, Blizzard KK, Zeng Z, DeVries AC, Hurn PD, McCullough LD. Chronic behavioral testing after focal ischemia in the mouse: functional recovery and the effects of gender. Exp Neurol. 2004;187:94-104.

14. Hartmann J, Blum R, Kovalchuk Y, et al. Distinct roles of Galpha(q) and Galpha11 for Purkinje cell signaling and motor behavior. J Neurosci. 2004;24: 5119-5130. 
15. Maier CM, Sun GH, Kunis D, Yenari MA, Steinberg GK. Delayed induction and long-term effects of mild hypothermia in a focal model of transient cerebral ischemia: neurological outcome and infarct size. J Neurosurg. 2001; 94:90-96.

16. Wang GJ, Deng HY, Maier CM, Sun GH, Yenari MA. Mild hypothermia reduces ICAM-1 expression, neutrophil infiltration and microglia/monocyte accumulation following experimental stroke. Neuroscience. 2002;114:1081-1090.

17. Kelly S, Zhao H, Hua Sun G, et al. Glycogen synthase kinase 3beta inhibitor Chir025 reduces neuronal death resulting from oxygen-glucose deprivation, glutamate excitotoxicity, and cerebral ischemia. Exp Neurol. 2004;188:378-386.

18. Yenari MA, Xu L, Tang XN, Qiao Y, Giffard RG. Microglia potentiate damage to blood-brain barrier constituents: improvement by minocycline in vivo and in vitro. Stroke. 2006;37:1087-1093.

19. Arvin KL, Han BH, Du Y, Lin SZ, Paul SM, Holtzman DM. Minocycline markedly protects the neonatal brain against hypoxic-ischemic injury. Ann Neurol. 2002;52:54-61.
20. Morimoto N, Shimazawa M, Yamashima T, Nagai H, Hara H. Minocycline inhibits oxidative stress and decreases in vitro and in vivo ischemic neuronal damage. Brain Res. 2005;1044:8-15.

21. Zhu S, Stavrovskaya IG, Drozda M, et al. Minocycline inhibits cytochrome c release and delays progression of amyotrophic lateral sclerosis in mice. Nature. 2002;417:74-78

22. Fox C, Dingman A, Derugin N, et al. Minocycline confers early but transient protection in the immature brain following focal cerebral ischemia-reperfusion. J Cereb Blood Flow Metab. 2005;25:1138-1149.

23. Yang DJ, Kim EE, Inoue T. Targeted molecular imaging in oncology. Ann Nucl Med. 2006;20:1-11.

24. Belhocine TZ, Blankenberg FG. ${ }^{99 \mathrm{~m}} \mathrm{Tc}-$ Annexin A5 uptake and imaging to monitor chemosensitivity. Methods Mol Med. 2005;111:363-380.

25. Tran N, Poussier S, Franken PR, et al. Feasibility of in vivo dual-energy myocardial SPECT for monitoring the distribution of transplanted cells in relation to the infarction site. Eur J Nucl Med Mol Imaging. 2006;33:709-715. 